\title{
Open reduction and endobutton fixation of displaced fractures of the lateral end of the clavicle in younger patients
}
C. M. Robinson, M. A. Akhtar, P. J. Jenkins, T. Sharpe, A. Ray, B. Olabi

From The Shoulder Injury Clinic, Edinburgh Orthopaedic Trauma Unit, Edinburgh, Scotland

\author{
Displaced fractures of the lateral end of the clavicle in young patients have a high incidence of \\ nonunion and a poor functional outcome after conservative management. Operative \\ treatment is therefore usually recommended. However, current techniques may be associated \\ with complications which require removal of the fixation device. We have evaluated the \\ functional and radiological outcomes using a novel technique of open reduction and internal \\ fixation. A series of $\mathbf{1 6}$ patients under $\mathbf{6 0}$ years of age with displaced fractures of the lateral \\ end were treated by open reduction and fixation using a twin coracoclavicular endobutton \\ technique. They were followed up for the first year after their injury. \\ At one year the mean Constant score was 87.1 and the median Disabilities of the Arm, \\ Shoulder and Hand score was 3.3. All fractures had united, except in one patient who \\ developed an asymptomatic fibrous union. One patient had post-traumatic stiffness of the \\ shoulder, which resolved with physiotherapy. None required re-operation. \\ This technique produces good functional and radiological outcomes with a low \\ prevalence of complications and routine implant removal is not necessary.
}

Most fractures of the lateral end of the clavicle are minimally displaced and heal with good functional outcome when treated nonoperatively. ${ }^{1-5}$ Fractures with complete displacement are less common. but have a higher risk of subsequent nonunion. ${ }^{1-3,6-8}$ Most displaced fractures occur in elderly patients, many of whom have low functional demands and may have a satisfactory outcome after nonoperative treatment. ${ }^{4,9,10}$ A minority of patients are younger, and fare less well with non-operative treatment. ${ }^{4}$ Persistent pain, restriction of movement and loss of strength and endurance of the shoulder may develop if the fracture fails to heal. ${ }^{1,11,12}$ Because reconstruction of an established nonunion may be technically challenging, operation is frequently recommended as a primary treatment. ${ }^{7}$

A wide variety of operative techniques have been described to treat these injuries, the most popular of which are coracoclavicular screws $^{13,14}$ and hook plates, ${ }^{15-17}$ and more recently, tailor-made lateral clavicular plates. Although primary operative treatment may reduce the risk of subsequent nonunion it carries its own complications, including hardware failure and infection. In addition, many of these implants are relatively rigid and may restrict acromioclavicular movement, leading to limited movement in the shoulder. Most authors therefore recommend routine removal of these implants once the fracture has united. 13,18,19 Coracoclavicular loops and slings of synthetic materials, allograft and autograft are less rigid and have been used in the treatment of acromioclavicular separations. ${ }^{20}$ In most instances, subsequent removal of the implant is not required. However, the use of these techniques in the treatment of displaced lateral clavicular fractures is less well defined. $^{21-25}$

The aim of this study was to assess prospectively the functional and radiological outcomes, and the prevalence of complications, after early operative intervention in patients under 60 years of age with acute displaced fractures of the lateral end of the clavicle. We adopted an operative protocol of open reduction and fixation using a novel twin endobutton implant to maintain reduction until union of the fracture.

\section{Materials and Methods}

Between January 2007 and June 2008 we prospectively studied a consecutive series of 16 locally resident patients with a displaced fracture of the lateral aspect of the clavicle. Only medically fit patients aged less than 60 years who were seen within three weeks of the injury were considered. The fracture had to 
be completely displaced, with no residual cortical contact, and located in the portion of the clavicle lateral to a vertical line drawn upwards from the base of the coracoid process.

During the study period, 14 patients aged over 60 were treated for displaced fractures. Their treatment was individualised according to their physiological status, with three more active patients treated operatively and 11 less active ones treated non-operatively. As the treatment of the latter was not protocol driven, they were excluded from the study. During the study period an additional 42 patients of all ages sustained an acute fracture of the lateral aspect of the clavicle which was either incompletely displaced with residual cortical contact (20 patients) or undisplaced (22 patients). They were excluded from the study. Four further patients with displaced fractures were excluded because they were referred more than three weeks after injury. One locally resident patient was treated operatively, but defaulted from any follow-up and became untraceable.

The mean age of the remaining patients was 38.3 years $(15$ to 56); all were male. The fractures were sustained during sport in 12 patients, following a fall at home in two and a fall from more than two metres in two. There were no open fractures and no patient had pre-operative neurovascular compromise. No patient had a concomitant fracture of the scapula or of the proximal humerus. Two patients had minor head injuries and five had ipsilateral rib fractures.

Initial treatment protocol and assessment of the anatomical features of the injuries. We obtained standardised preoperative radiographs of anteroposterior and Velpeau views at the initial presentation. The anatomical features of the fractures were classified using the Craig modification of the Neer classification $^{26}$ and the Edinburgh classification systems. ${ }^{3}$ Six fractures were Craig/Neer type IIA (conoid and trapezoid intact and attached to the lateral fragment), three fractures were type IIB (conoid torn, trapezoid intact and attached to lateral fragment), and three were type $\mathrm{V}$ (both ligaments attached to a third inferior bony fragment). The remaining four fractures had articular involvement and were type III. A total of 12 fractures were Edinburgh type 3B1 (displaced extra-articular) and four were type 3B2 (intra-articular).

Operative technique. All operations were performed under general anaesthesia in the beach-chair position by the senior author (CMR). Standard antithrombotic and antibiotic prophylaxis was used. The procedure was performed at a mean of six days after injury (2 to 15$)$. The mean duration of surgery was 40 minutes (30 to 75 ), and the mean blood loss was $80 \mathrm{ml}$ (60 to 120$)$.

The skin incision was infiltrated with 1:200 000 epinephrine solution to reduce cutaneous bleeding. A $6 \mathrm{~cm}$ vertical ('bra-strap') incision was made with its base centred on the coracoid process (Fig. 1a). The deltotrapezius fascia was incised perpendicular to the incision and released by sharp dissection from the clavicle to expose the fracture. Using a $4.5 \mathrm{~mm}$ cannulated drill, bone tunnels were made in the clavicle $15 \mathrm{~mm}$ medial to the fracture site and centrally in the coracoid, $20 \mathrm{~mm}$ from its tip (Figs $1 \mathrm{~b}$ and 1c).
The lower tunnel was created under direct vision by splitting the deltoid in the lower aspect of the wound to reduce the risk of eccentric tunnel placement. This tunnel was drilled perpendicular to the flat superomedial surface of the coracoid between $30^{\circ}$ and $45^{\circ}$ to the coronal plane (Fig. 1c).

The endobutton construct consists of two endobuttons (Smith and Nephew, London, United Kingdom) loaded with a \#2 Orthocord (Ethicon, Edinburgh, United Kingdom) suture. The core suture is looped twice through the buttons, creating a six-ply sliding pulley effect. The lower button of the implant is passed through the clavicle and coracoid, and then toggled on the under-surface of the coracoid (Fig. 1d). The fracture is then reduced under direct vision and the suture tensioned. We confirmed accurate reduction and toggling of the lower endobutton below the coracoid fluoroscopically before tying the suture ends over the proximal endobutton (Fig. 1e). The arm was rested in a sling for four weeks after surgery. The patients then started physiotherapy which continued until a full range of shoulder movement was regained.

Outcome assessment. The chief outcome measures in this study were function, the radiological outcome and the prevalence of fracture-related complications within the first year of surgery.

The patients were evaluated at one and six weeks, and at three, six and 12 months after their injury. The Short Form-36 (SF-36) general health questionnaire, ${ }^{27,28}$ the upper limb-specific Disabilities of the Arm, Shoulder and Hand (DASH) questionnaire ${ }^{29}$ and the shoulder-specific Constant score ${ }^{30}$ were competed with the help of a research worker (MAA) at six weeks, and at three, six and 12 months after injury. We also recorded whether the patient had returned to work or to normal daily activities. We recorded the range of movement in the shoulder and tested for weakness of the rotator cuff and superior labral dysfunction, ${ }^{31-34}$ impingement lesions, ${ }^{35-37}$ and for signs of dysfunction of the acromioclavicular joint. ${ }^{34,38}$

Displacement of the fracture was assessed at each followup, by measuring the vertical displacement of the most superior element of the diaphyseal fragment from the most superior element of the lateral fragment on anteroposterior radiographs, adjusting for magnification artefact. We considered fractures to be united if the patient had no pain or only mild activity-related discomfort in the shoulder, and there were no radiological signs of loss of reduction, implant loosening or breakage, or resorption at the fracture site.

\section{Results}

Complications. There were no early post-operative complications. No patient underwent further surgery during the period of review. A 55-year-old patient developed a fibrous union with no signs of bridging callus at the fracture site. This was confirmed using CT scanning six months after injury. There was no radiological evidence of loss of reduction or displacement of either endobutton. He had no shoulder pain or functional disability, and was unwilling to undergo further surgery. 


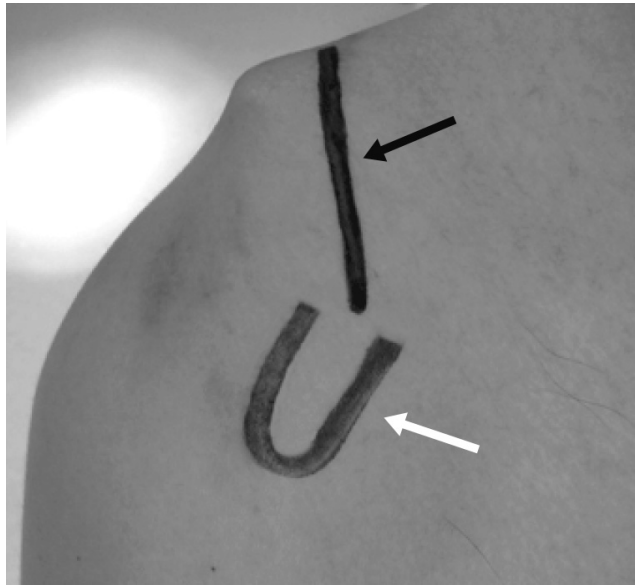

Fig. 1a

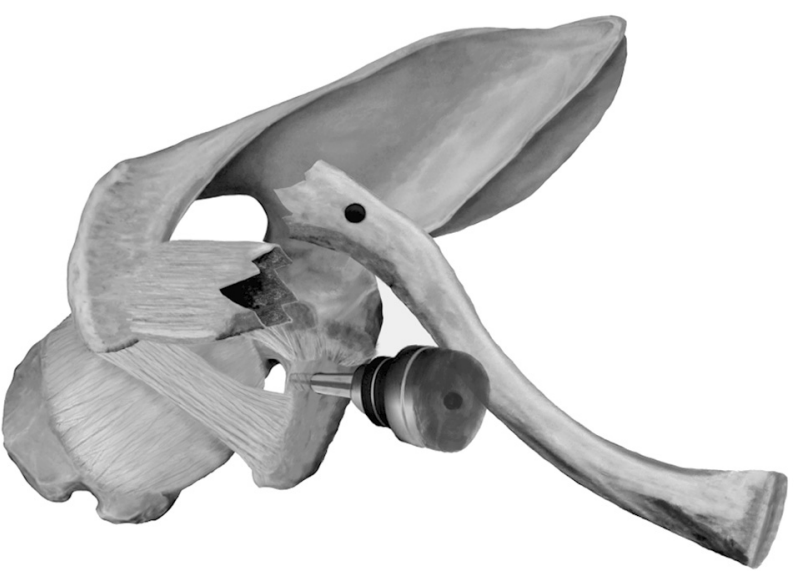

Fig. 1c

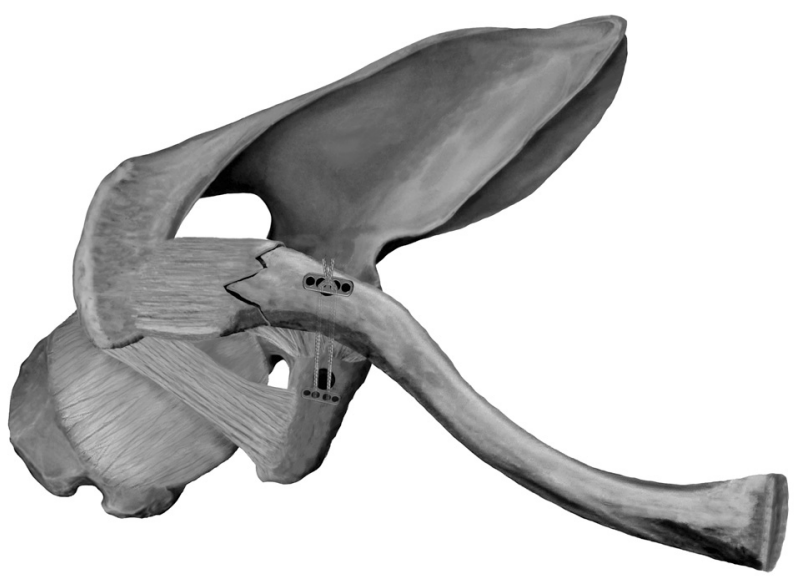

Fig. 1e

He remains asymptomatic, two years later despite a persistent fibrous union. One 40-year-old patient had shoulder stiffness three weeks after removal of the sling, with loss of $20^{\circ}$ of external rotation and $20^{\circ}$ of combined abduction, but follow-

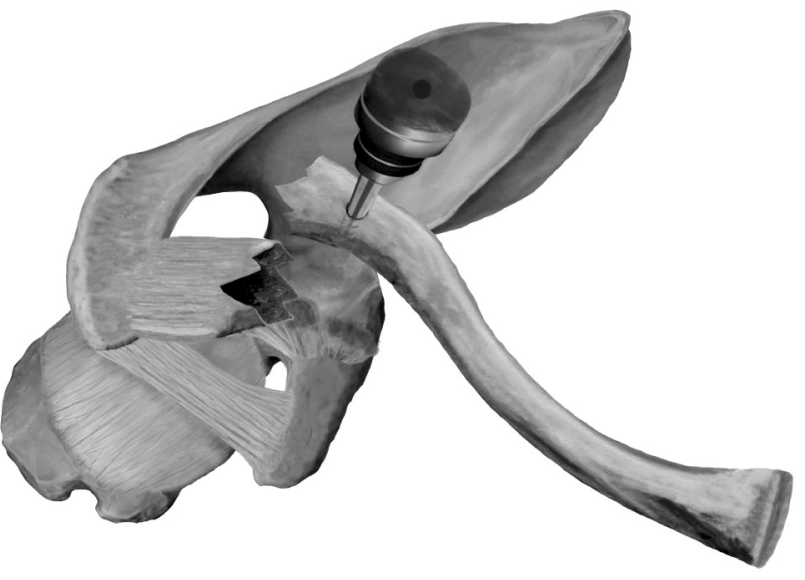

Fig. 1b

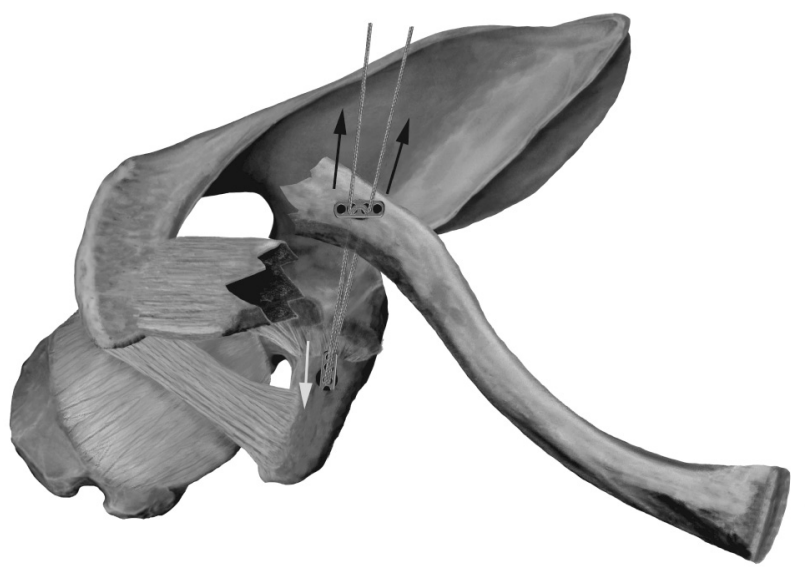

Fig. 1d

The key steps of the operative technique, a) a vertical shoulder strap incision is used (black arrow), with its base on the surface marking of the coracoid (white arrow). The deltotrapezius fascia is incised perpendicular to the line of the incision, b) the tunnel in the clavicle is created using a $4.5 \mathrm{~mm}$ cannulated drill bit, c) the coracoid tunnel is created under direct vision through a split in the anterior deltoid, using the same drill bit. Note that the superior surface of the coracoid faces $30^{\circ}$ to $45^{\circ}$ superomedially, and the tunnel should be created perpendicular to this surface, $d$ ) the endobutton construct is 'railroaded' through the two tunnels (white arrow). The lower button is then toggled against the undersurface of the coracoid. The fracture is reduced by sequential tensioning on the two free suture ends (black arrows) and e) the suture ends are tied once the fracture is reduced both under direct vision and on fluoroscopic views.

ing physiotherapy he had regained a full range of movement by three months.

Functional outcome. Some patients missed one or more follow-up appointments, but a final assessment was 


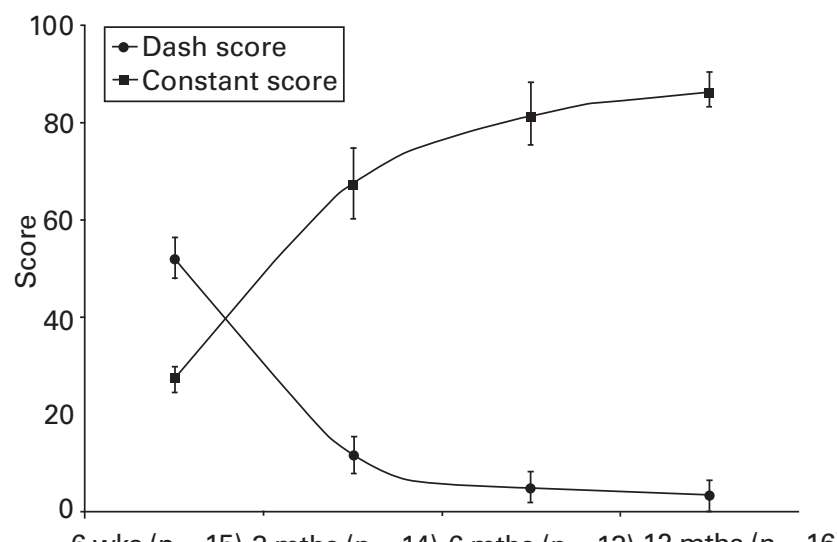

6 wks $(n=15) 3$ mths $(n=14) 6$ mths $(n=13) 12$ mths $(n=16)$

Time since surgery

Fig. 2

Graph showing the recovery of functional outcome in the first two years after injury, using the Constant and Disabilities of the Arm, Shoulder and Hand (DASH) scores. A high Constant score denoted better function, with a theoretically 'perfect' score of 100. A lower DASH score denotes better function, with a theoretically 'perfect' score of 0 .

obtained at one-year for all 16. The mean DASH and Constant scores showed continued significant improvement within the first six months after injury (Wilcoxon's matched-pairs test, $\mathrm{p}=0.02 ; \mathrm{p}=0.01$ at three months, $\mathrm{p}=0.04 ; \mathrm{p}=0.02$ at six months, Fig. 2), but there was no statistically significant difference between the six-month and one-year measurements. At one year after surgery the mean Constant score was 87.1 points $(95 \%$ confidence interval (CI) 83.6 to 90.6) and the median DASH score was 3.3 points ( $95 \%$ CI 0 to 6.7 ). With the numbers available, there was no significant difference $(p=0.6)$ in outcome between dominant and non-dominant injured shoulders.

At one year, 15 patients had no pain in their shoulder; one had mild pain, which was not activity related. The mean combined forward flexion at one year was $172.3^{\circ}$ $\left(160^{\circ}\right.$ to $\left.180^{\circ}\right)$ and the mean combined abduction was $173^{\circ}\left(140^{\circ}\right.$ to $\left.180^{\circ}\right)$ and the mean internal rotation was $80^{\circ}$ $\left(60^{\circ}\right.$ to $\left.100^{\circ}\right)$. No patient had evidence of rotator cuff weakness or impingement, or signs of posterior glenohumeral joint instability on clinical testing at the oneyear follow-up. No patients had symptoms or signs referable to the acromioclavicular joint on specific testing.

All 16 patients were in regular employment before their injury. By three months the 13 who had been employed in a sedentary job prior to the injury had all returned to their full work duties and normal daily activities. The remaining three, who were manual workers had all returned to work by six months. The mean time lost from work after the injury was 21 days (7 to 50 ).

Of the 12 patients who played regular sports (seven contact, five non-contact) prior to their injury, all but two had returned to playing by six months. Of the two patients who had not returned at six months, one returned by one year and the other

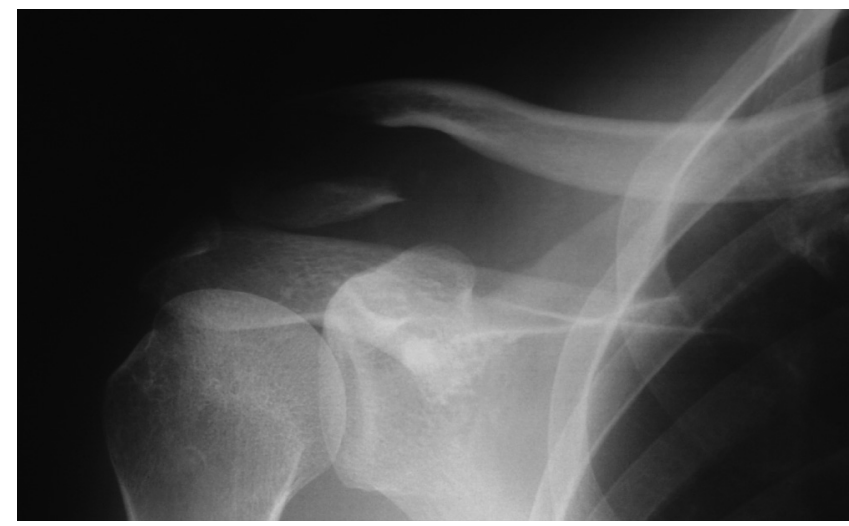

Fig. 3a

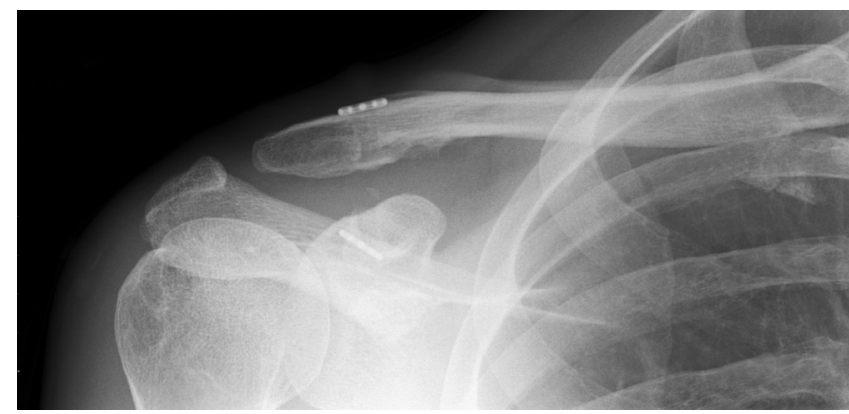

Fig. $3 b$

Pre-operative radiograph of a) a displaced fracture of the lateral end of the clavicle in a 31-year-old man who sustained his injury in a fall from a bicycle. At exploration this was confirmed to be a displaced extra-articular fracture with partial disruption of the coraclavicular ligaments (Neer type IIB Edinburgh type 3B1) and b) Radiograph taken one year after injury, showing maintenance of reduction and bony consolidation at the fracture site.

had downgraded to non-contact sports. The mean number of physiotherapy sessions during rehabilitation was 3.5 ( 0 to 35 ). Radiological outcome. The mean initial displacement of the fracture was $20 \mathrm{~mm}$ (18 to 25$)$. The mean residual displacement post-operatively was $1 \mathrm{~mm}(-2$ to +4$)$. There were no failures of fixation and no loss of the reduction during the first year after surgery. Apart from the patient with a clearly demonstrable residual gap, all the remaining fractures showed clear evidence of reduction of the fracture gap and remodelling at final follow-up (Fig. 3). There was radiological evidence of mild ectopic bone formation on the undersurface of the clavicle in six patients, but complete synostosis to the coracoid did not occur. There was evidence of mild acromioclavicular joint osteoarthrosis on pre-operative radiographs in three cases; none of these patients had symptoms related to this prior to their injury. There was no radiological evidence of progression of the osteoarthrosis at one year.

\section{Discussion}

The results of this study suggest that open reduction and endobutton fixation for isolated displaced fractures of the lateral end of the clavicle in younger patients is associated 
with a high probability of bony union and a low risk of complications. Most patients regained near-normal shoulder function and range of movement during the first six months after the injury, and had returned to their pre-injury occupation and leisure pursuits. To our knowledge, this is the first study to evaluate the results of this technique prospectively in a small but well-defined younger population, with evaluation of function one year after the injury.

A major advantage of this technique is that further surgery to remove the implant after the fracture has united is not needed. Despite retaining the implant in all our patients, only one developed minor shoulder stiffness, which resolved after a short period of physiotherapy. Most other techniques to treat these injuries, including coracoclavicular screw fixation and hook-plate devices, have been adapted from those used to treat acromioclavicular dislocation. ${ }^{19,20}$ These techniques provide rigid fixation, which may lead to stiffness of the shoulder if the implant is retained. Most authors therefore recommend removing it. ${ }^{13,18,19}$ However, early removal of the implant may increase the risk of re-displacement of the fracture if there is incomplete union, whereas prolonged retention of the implant may produce intractable shoulder stiffness. ${ }^{19}$

Displaced fractures of the lateral end of the clavicle are unstable injuries and are frequently associated with nonunion, which may cause functional compromise in younger adults and middle-aged patients. These injuries may be double disruptions of the superior shoulder suspensory complex, when the fracture occurs in association with disruption of the coracoclavicular ligaments. ${ }^{39}$ For this reason some authors have advocated the use of other coracoclavicular loop and sling techniques using autograft, allografts or prosthetic ligaments to reconstruct these ligaments. ${ }^{19} \mathrm{How}^{-}$ ever, it is our experience that these ligaments are frequently only partially disrupted (Neer type IIB injury), or intact, with the majority of the ligament complex remaining attached either to the lateral fragment (Neer type IIA injury), or to a third inferior fragment (Neer type $\mathrm{V}$ injury). We therefore feel that primary ligamentous reconstruction is unnecessary in most patients. It was our intention that the endobutton construct should function as an internal fixation' device to maintain reduction while the fracture united, rather than as a ligamentous augmentation. The fact that secondary instability of the superior shoulder suspensory complex did not occur in our series lends support to this contention.

Newer 'custom-made' endobutton constructs are available, such as the Tightrope system (Arthrex, Sheffield, United Kingdom). ${ }^{20,40-43}$ No detailed clinical evaluation of these implants has so far been described in large series. Their use has been advocated in acute and chronic acromioclavicular separations, Rockwood grade III and above. ${ }^{20,40-43}$ However, it has been our experience that additional ligamentous augmentation is usually required in these patients, as the degree of ligamentous disruption to both the coraco- and acromioclavicular liga- ments is greater. We therefore cannot advocate the extension of our technique to the treatment of these injuries.

Minimally invasive closed reduction and arthroscopic insertion of a similar endobutton construct has been described. ${ }^{44-46}$ However, we feel that this procedure is best performed as an open surgical exposure. It has been our experience that obtaining an accurate reduction of twopart fractures may be difficult, owing to the complex pattern of inferior displacement of the shoulder girdle, combined with retraction of the diaphyseal fragment, frequently with 'button-hole' of the deltotrapezius fascia. Infolding of periosteum at the fracture site is also frequently encountered and may initially prevent accurate reduction. We have also found that intra-operative fluoroscopic views are often misleading and that an accurate reduction is easier to obtain under direct vision. In addition, the superior coracoid pillar averages only $14.2 \mathrm{~mm}$ (11 to 19 in 102 scapulae) in breadth and its flat superior surface is inclined $45^{\circ}$ medially in the coronal plane. ${ }^{47}$ Accurate placement of a bone tunnel centrally within the coracoid may be difficult using arthroscopic techniques, even when a jig is employed. Eccentric tunnel placement increases the risk of implant cut-out and failure. We therefore prefer to drill the coracoid tunnel under direct vision, to ensure central placement within the pillar. The size of the incision for the open surgical approach is scarcely larger than the combined sizes of the incisions using an arthroscopic technique and cosmetically there is little to choose between the two.

Although a prospective evaluation of outcome was performed during the first year after injury, no direct comparison with other more established techniques was made. We are therefore uncertain whether the low rates of secondary surgery and complications produce better function than other existing techniques. Although the operative technique is relatively simple, there is a learning curve, and as this study was a single-surgeon series it is unclear whether the satisfactory results would be generalisable. A number of late complications have been described which may be associated with the use of similar techniques, including re-fracture of the clavicle and stress fracture of the coracoid. ${ }^{19}$ Furthermore, generic complications, including acromioclavicular osteoarthrosis, may take longer to develop. Although these complications have so far not been encountered in our patients, long-term follow-up would be required to assess the true incidence of complications.

No benefits in any form have been received or will be received from a commercial party related directly or indirectly to the subject of this article.

\section{References}

1. Neer CS 2nd. Fractures of the distal third of the clavicle. Clin Orthop 1968;58:43-50.

2. Nordqist A, Petersson C, Redlund-Johnell I. The natural course of lateral clavicle fracture: 15 (11-21) year follow-up of 100 cases. Acta Orthop Scand 1993;64:87-91.

3. Robinson CM. Fractures of the clavicle in the adult: epidemiology and classification. J Bone Joint Surg [Br] 1998;80-B:476-84.

4. Robinson CM, Cairns DA. Primary nonoperative treatment of displaced lateral fractures of the clavicle. J Bone Joint Surg [Am]2004;86-A:778-82. 
5. Robinson CM, Court-Brown CM, McQueen MM, Wakefield AE. Estimating the risk of nonunion following nonoperative treatment of a clavicular fracture. $J$ Bone Joint Surg [Am]2004;86-A:1359-65

6. Neer CS 2nd. Fracture of the distal clavicle with detachment of the coracoclavicular ligaments in adults. J Trauma 1963;3:99-110.

7. Edwards DJ, Kavanagh TG, Flannery MC. Fractures of the distal clavicle: a case for fixation. Injury 1992;23:44-6.

8. Kavanagh TG, Sarkar SD. Complications of displaced fractures of the outer end of the clavicle. J Bone Joint Surg [Br] 1985;67-B:492-3.

9. Deafenbaugh MK, Dugdale TW, Staehli JW, Nielsen R. Nonoperative treatment of Neer type II distal clavicle fractures: a prospective study. Contemp Orthop 1990;20:405-13.

10. Rokito AS, Zuckerman JD, Shaari JM, et al. A comparison of nonoperative and operative treatment of type II distal clavicle fractures. Bull Hosp Jt Dis 2002;61:32-9.

11. Eskola A, Vainionpää S, Pätiälä H, Rokkanen P. Outcome of operative treatment in fresh lateral clavicular fracture. Ann Chir Gynaecol 1987;76:167-9.

12. Jupiter JB, Leffert RD. Non-union of the clavicle: associated complications and surgical management. J Bone Joint Surg [Am] 1987;69-A:753-60.

13. Ballmer FT, Gerber C. Coracoclavicular screw fixation for unstable fractures of the distal clavicle: a report of five cases. J Bone Joint Surg [Br] 1991;73-B:291-4.

14. Macheras G, Kateros KT, Savvidou OD, et al. Coracoclavicular screw fixation for unstable distal clavicle fractures. Orthopedics 2005;28:693-6.

15. Flinkkilä T, Ristiniemi J, Hyvönen $\mathbf{P}$, Hämäläinen $\mathbf{M}$. Surgical treatment of unstable fractures of the distal clavicle: a comparative study of Kirschner wire and clavicular hook plate fixation. Acta Orthop Scand 2002;73:50-3.

16. Flinkkilä T, Ristiniemi J, Lakovaara M, Hyvönen P, Leppilahti J. Hook-plate fixation of unstable lateral clavicle fractures: a report on 63 patients. Acta Orthop 2006;77:644-9.

17. Mizue F, Shirai Y, Ito $\mathbf{H}$. Surgical treatment of comminuted fractures of the distal clavicle using Wolter clavicular plates. J Nippon Med Sch 2000;67:32-4.

18. Yamaguchi H, Arakawa H, Kobayashi M. Results of the Bosworth method for unstable fractures of the distal clavicle. Int Orthop 1998;22:366-8.

19. Khan LA, Bradnock TJ, Scott C, Robinson CM. Fractures of the clavicle. J Bone Joint Surg [Am] 2009;91-A:447-60.

20. Fraser-Moodie JA, Shortt NL, Robinson CM. Injuries to the acromioclavicular joint. J Bone Joint Surg [Br] 2008;90-B:697-707.

21. Hessmann M, Kirchner R, Baumgaertel F, Gehling H, Gotzen L. Treatment of unstable distal clavicular fractures with and without lesions of the acromioclavicular joint. Injury 1996;27:47-52.

22. Goldberg JA, Bruce WJ, Sonnabend DH, Walsh WR. Type 2 fractures of the distal clavicle: a new surgical technique. J Shoulder Elbow Surg 1997;6:380-2.

23. Levy $\mathbf{0}$. Simple, minimally invasive surgical technique for treatment of type 2 fractures of the distal clavicle. J Shoulder Elbow Surg 2003;12:24-8.

24. Webber MC, Haines JF. The treatment of lateral clavicle fractures. Injury 2000;31:175-9.

25. Shin Si, Roh KJ, Kim JO, Sohn HS. Treatment of unstable distal clavicle fractures using two suture anchors and suture tension bands. Injury 2009;40:1308-12.

26. Craig EV. Fractures of the clavicle. In: Rockwood CA Jr, Matsen FA 3rd, eds. The shoulder. Vol. 1. Philadelphia: WB Saunders, 1990:367-401.
27. Jenkinson C, Layte R, Wright L, Coulter A. The UK SF-36: an analysis and interpretation manual. Oxford: Health Services Research Unit, 1996.

28. Ware JE, Snow KK, Kosinski M, Gandek B. SF-36 health survey manual and interpretation guide. Boston: New England Medical Center, The Health Institute, 1993

29. Hudak PL, Amadio PC, Bombardier C. Development of an upper extremity outcome measure: the DASH (disabilities of the arm, shoulder and hand) [corrected] The Upper Extremity Collaborative Group (UECG). Am J Ind Med 1996;29:602-8.

30. Constant CR, Murley AH. A clinical method of functional assessment of the shoulder. Clin Orthop 1987;214:160-4

31. Jobe FW, Jobe CM. Painful athletic injuries of the shoulder. Clin Orthop 1983;173:117-24

32. Hertel R, Ballmer FT, Lombert SM, Gerber C. Lag signs in the diagnosis of rotator cuff rupture. J Shoulder Elbow Surg 1996;5:307-13.

33. Gerber C, Hersche $\mathbf{0}$, Farron A. Isolated rupture of the subscapularis tendon. $J$ Bone Joint Surg [Am] 1996;78-A:1015-23.

34. O'Brien SJ, Pagnani MJ, Fealy S, McGlynn SR, Wilson JB. The active compression test: a new and effective test for diagnosing labral tears and acromioclav iclar joint abnormality. Am J Sports Med 1998;26:610-13.

35. Neer CS 2nd. Impingement lesions. Clin Orthop 1983;173:70-7.

36. Hawkins RJ, Kennedy JC. Impingement syndrome in athletes. Am J Sports Med 1980;8:151-8.

37. Funk L, Gupta AK. The Copeland shoulder impingement test. J Bone Joint Surg [Br] 2005;87-B(Suppl II):161.

38. Park HB, Yokota A, Gill HS, El Rassi G, McFarland EG. Diagnostic accuracy of clinical tests for the different degrees of subacromial impingement syndrome. $J$ Bone Joint Surg [Am] 2005;87-A:1446-55.

39. Goss TP. Double disruptions of the superior shoulder suspensory complex. Orthop Trauma 1993;7:99-106.

40. Wellmann M, Zantop T, Petersen W. Minimally invasive coracoclavicular ligament augmentation with a flip button/polydioxanone repair for treatment of total acromioclavicular joint dislocation. Arthroscopy 2007;23:1132. e1-5.

41. Salzmann GM, Walz L, Schoettle PB, Imhoff AB. Arthroscopic anatomica reconstruction of the acromioclavicular joint. Acta Orthop Belg 2008;74:397-400.

42. Walz L, Salzmann GM, Fabbro T, Eichhorn S, Imhoff AB. The anatomic reconstruction of acromioclavicular joint dislocations using 2 TightRope devices: a biomechanical study. Am J Sports Med 2008;36:2398-406

43. Hosseini H, Friedmann S, Tröger M, Lobenhoffer P, Agneskirchner JD. Arthroscopic reconstruction of chronic AC joint dislocations by transposition of the coracoacromial ligament augmented by the Tight Rope device: a technical note. Knee Surg Sports Traumatol Arthrosc 2009;17:92-7.

44. Checchia SL, Doneux PS, Miyazaki AN, Fregoneze M, Silva LA. Treatment of distal clavicle fractures using an arthroscopic technique. J Shoulder Elbow Surg 2008;17:395-8.

45. Nourissat G, Kakuda C, Dumontier C, Sautet A, Doursounian L. Arthroscopic stabilization of Neer type 2 fracture of the distal part of the clavicle. Arthroscopy 2007;23:674

46. Pujol N, Philippeau JM, Richou J, et al. Arthroscopic treatment of distal clavicle fractures: a technical note. Knee Surg Sports Traumatol Arthrosc 2008;16:884-6.

47. Bhatia DN, de Beer JF, du Toit DF. Coracoid process anatomy: implications in radiographic imaging and surgery. Clin Anat 2007;20:774-84. 